\title{
The Advanced Added Skills Developed by Nurse Managers / Leaders in an Archipelago Region: Training Needs
}

\author{
Marlene Morais Ribeiro ${ }^{1,2}$ \\ ${ }^{1}$ Nursing School of Porto, University of Porto, Porto, Portugal \\ ${ }^{2}$ Emergency Service, Pico Island Health Unit, Azores, Portugal
}

Email address:

marlenemorais04@gmail.com

\section{To cite this article:}

Marlene Morais Ribeiro. The Advanced Added Skills Developed by Nurse Managers / Leaders in an Archipelago Region: Training Needs. American Journal of Nursing Science. Vol. 10, No. 4, 2021, pp. 209-215. doi: 10.11648/j.ajns.20211004.14

Received: May 13, 2021; Accepted: June 3, 2021; Published: July 21, 2021

\begin{abstract}
Health service organizations expect manager nurses to develop activities that foster the best quality results both in terms of assistance and in terms of management. To do so, managers have to master management skills. To understand the activity carried out by the manager nurses in an archipelago with several islands. Descriptive, analytical and exploratory study of quantitative nature. The data collection instrument was an autofill questionnaire, which included a Perception Scale of the Work of the Manager Nurses. The academic qualifications of the nursing managers are as follows: postgraduate studies in specific areas other than management (15,9\%); postgraduate studies in the field of management (36,5\%) and master's degree in different areas $(17,5 \%)$. The results in the field of the skills of management of nursing care may be the ones that require a bigger investment in terms of training. Regarding the skills in the field of political intervention and advice, the results observed were below expectations. The need for specific training in the field of management is quite obvious; we were able to prove that most of the manager nurses do not possess specific training in the field of management which would allow them to perform the management tasks based on solid knowledge.
\end{abstract}

Keywords: Skills of the Managing Nurse, Nursing Leadership, Quality of Caring Services

\section{Introduction}

An island region stands out by its singularities and idiosyncrasies, a fact that determines that the existing health organizations throughout an archipelago of nine islands are also singular, thus turning the nursing research indisputable, within the scope of the activity and training needs in the area of management of Manager and Leader Nurses.

The multiple demands, the changing environments and scientific and technological advances require a substantial increase in the responsibilities of Manager Nurses, which requires a continuous redefinition of their functions and roles, and a careful attention at the evolution of their skills [1].

Observing implies a zoom view on management, since this is a complex activity that requires reflection upon the models of management intervention, which implies discussing training needs versus skills. "At present skills are an extremely relevant and powerful vector in management processes. This importance becomes even more visible, if we talk about human resources management and people management" [2].
The current management models have demonstrated the importance of participatory management of all the organizations' stakeholders, a transversal reality in the health area, however, for this participation to be valid, the Manager Nurses are required to prepare and master skills that demonstrate its usefulness in the management process.

In this context, the research process was conducted with the following aims: Understanding the activity of Nurse Managers in an island region, and identifying areas of training that promote advanced skills of nursing managers.

\section{Skills of Nursing Managers}

It is undeniable that the training in the field of management is a relevant premise and had a direct influence in their leadership style, promoting self-reflection and consequently taking steps that are more appropriate to their work contexts.

Ceitil [2] defines competence as "the set of social and communicational learning, fueled by learning and training and complemented by the evaluation system that later allows 
updating competence and introducing the necessary improvements" [2].

Much of the management in nursing is to take the team to provide the best care with the available resources so that "managers with human capabilities manage to get the best out of others, as they know how to communicate, motivate, lead, managing to transmit a motivating enthusiasm and confidence to others " [3].

Involving followers beyond expectations, establishing leadership authority and integrity, while inspiring and motivating subordinates is the role of Nurse Managers. In this context, the main leadership skills include idealized influence, inspired motivation, intellectual stimulation and individual consideration, Chipeta, E., Bradley, S., Manda, W., McAuliffe, E. [4] state that the main indicators of motivation and organizational performance are leadership practices and they also acknowledge that these practices have an increasingly significant dimension in the quality results in health care.

Moura, A., Bernardes, A. \& Balsanelli, A. [5] advocates that the leader in nursing, acts as the one who allows frank and open communication, who has the ability to recognize and meet the needs of the team, knows how to support when needed, fosters harmony in the work environment; someone who works for the union and integration of the team, ensuring the satisfaction of nurses and, consequently, the quality of care provided to clients.

Costa, T. [3] adds that managers add value to resources by influencing the people with whom they interact. The function of planning, organizing, directing and controlling depends on the participation of all those involved to collaborate in a network of mutual influence. It shows that a leader is someone who can influence others and has the skills to do so.

Camelo, S., Silva, V., Soares, M., Resck, Z., Chaves, 1., Santos, F. [6] establish as a starting point the premise that the manager nurse needs to lead his working team in order to achieve success, thus enabling the use of leadership as an essential skill. In this perspective, we agree that the improvement of these skills by combining them with the models of other managers and targeted training are strategies that will help gain leadership skills that are required for the Manager Nurse.

Munyewende, P., Levin, J. \& Rispel, L. [7] define competence as technical skills, knowledge and attitudes necessary to perform a job. They reveal the skills in strategic, financial and human resources management; innovation in the provision of services; customer orientation and focus; and communication as an essential asset to achieve organizational goals.

Specific skills, as the name implies, are those that are required for more restricted activities or contexts, usually associated with technical and instrumental domains. Regarding the management skills, other researchers identify three types of skills essential to the activity of managing: technical skills, human skills and conceptual skills [2, 3].

Conceptual skills are the skills that managers use to ponder and conceptualize about abstract and complex positions. Ceitil
[2] states that managers with this type of skills are able to visualize the organization as a whole, coordinate and integrate the interests and activities of the organization. These skills are especially important in top management.

However, there are other skills that assume increasing importance and that managers are required to have, such as: the ability to manage human capital, change, the decision-making process, strategy, innovation, logistics, and technology, among others [3].

We agree that health systems with a degree of complexity require manager nurses to have additional skills such as those outlined here in order to promote effective planning, guidance, coordination and control management. We cannot underestimate that management skills are very important to improve the quality of nursing care for the customer.

As a manager nurse one cannot neglect the centrality of his practice as a nurse. We should remember that the Regulation of Professional Nursing Practice (REPE) [8] defines and highlights the fundamental role of nurses as professionals with scientific, technical and human skills to provide care to people, during their life cycle. We should understand a person as a holistic being that integrates and interacts with his/her family, group or community, requiring care aimed at health promotion and disease prevention at its different levels of prevention (Dec Law no. 161/96, of 4 September, amended by Decree Law no. 104/98, of 21 April) [9].

It is important to remember that the manager nurse, has an added requirement, legally expressed in 2015, in Portugal, with the publication of the regulation of the skills of the manager nurse, Advanced Competence in Management is regulated through of Regulation No. 101/2015 [10]; and in January 2018, Advanced Competence in Management is regulated through of Regulation No. 76/2018 (DR, 2nd Series - No. 21, 2018) [11].

The current legislation that introduces changes to the career of a manager nurse, are stated in the Dec. Law No. 71/2019 of 27 May. Art. 10B - Regarding the functional content of the manager nurse, it establishes "... the functional content generally integrates the roles of planning, organization, direction and evaluation of nursing care, using a model that facilitates organizational development and promotes quality and security..." [12] (Dec. Law n $71 / 2019$, p. 2628). The manager nurse will have to perceive the new management concepts, and know how to be and how to act as a nurse in the face of challenges. However, during management procedures there are opportunities where nurse managers can be the main actors in the organization and successfully make a strategic change.

\section{Research question}

Is it possible that nurse managers in the island region develop the increased skills promoted in their area of expertise?

\section{Methodology}

Due to the lack of data about the situation under study, we designed a descriptive, exploratory study with a quantitative 
approach. The population is made up of all Nurse Managers (top managers, subsistent categories and exercising leadership roles) in the units that compose the sample and that at the same time are on duty during the data collection period, in a total of 63 participants from the 102 nurses that make up the population, representing $61.76 \%$ of this population, from 3 hospitals, 8 health units, 2 mental institutions and 4 nursing homes.

The data collection inquiry consists of two parts. The first alludes to sociodemographic and professional data (gender, age, years of professional practice, years of practice in the management area, years in the current service, area of expertise, academic degrees, nature of the institution and nature of the exploitation). The second part is part of the Nursing Manager's Job Perception Scale (EPTGE - Martins, MM; Gonçalves, MN, 2012), organized with 5 questions unfolded with activities developed in the management area, having as reference the advanced skills of the manager nurse of the Portuguese Order of Nurses (ON), consisting of 43 items whose answers are given on a Likert scale that allows assessing the dimensions of the manager nurses' activities: Professional, ethical and legal practice (5 activities ranging from 5 to 20 points), Care Management (14 activities ranging from 14 to 56 points), Human Resources Management (14 activities ranging from 14 to 56 points), Political Intervention and Advisory (6 activities ranging from 6 to 24 points), Professional Development (4 activities with variation from 4 to 16 points) and each activity was classified as: never (1 point), a few times ( 2 points), sometimes ( 3 points) and always (4 points). A four-point scale was chosen to avoid the option of central tendency in responses.

The scores for each of the subscales are calculated from the sum of each of the items belonging to each subscale. Overall, the scale can vary from 43 to 172 points, in which 43 corresponds to not doing management activities and 172 to doing management activities according to the best representation of these activities. The original scale has an Alpha value for the entire questionnaire which is 0.95 , a very high value, and shows a very strong internal consistency of the scale. A sample calculation was performed, with a $95 \%$ confidence level which exposes a margin of error of $7.67 \%$, resulting in a sample of 63 individuals.

Authorization to use the EPTGE scale was obtained from the authors and authorization to collect data was collected by the Boards of Directors of the 17 Health institutions and favorable opinions from their ethics committees. Clarification contacts were made to the manager nurses about the objectives, purposes and pertinence of the study.
Considering the territorial dispersion, the scale was delivered in digital format and made available through a link. The online platform chosen was Google forms ${ }^{\circledR}$ which was later imported into the statistical data treatment program - SPSS $®$.

Participation was requested after informed consent. The anonymity and confidentiality of the data collected was guaranteed, respecting the autonomy and also the freedom of participation and the possibility of wanting to give up at any time was given. Data collection took place in the period between 1 October 2018 and 28 February 2019.

\section{Results}

The majority of nurse managers are female (61.9\%). Age varies from 25 years to a maximum of 65 years, with an average age of 47.37 years. The years of professional practice range from 4 years to a maximum of 40 years, with an average of 23.47 years of professional practice. The number of years of practice in the management area varied between 0 and 31 years, with an average of 9.38 years. The number of years in the current service varies between 0 and 32 years with an average of 9.37 years. The area of specialty of the manager nurse found that the title of specialist nurse in Medical-Surgical is predominant with $(28.6 \%)$, followed by the title of specialist nurse in Community with (14.3\%). Therefore, in relation to the Academic Degree (81\%) of nurse managers have a degree, $(17.5 \%)$ have a Master's degree and (1.6\%) hold a PhD. The nature of the most representative institution is Hospitals with (54\%), followed by Island Health Units with $(25.4 \%)$ and the other institutions are represented in a minority $(20.6 \%)$. The most expressive nature of exploration is in the public sector $(82.5 \%)$ followed by the other sectors $(17.4 \%)$.

By analysing the results obtained, one can verify that the skills developed by the Manager Nurses allow them to develop tasks that can be considered very positive in terms of Professional Practice Ethics and Legal. When analyzing this component, in a quantitative perspective, we see a variation of 14 to 20 , with the mode at 20 and the average at 19.50 with a standard deviation of 1,667. However its distribution does not follow the normal curve. The values of the frequencies with the highest incidence are verified in the positive pole of the subscale, which can ensure that managers who were part of the sample are all above the midpoint of the subscale and an average higher than the midpoint (Table 1).

Table 1. Professional Ethical and Legal Practice.

\begin{tabular}{|c|c|c|c|c|c|c|c|c|c|c|}
\hline \multirow{2}{*}{ Dimensions } & \multicolumn{2}{|c|}{ Never } & \multicolumn{2}{|c|}{ Few times } & \multicolumn{2}{|c|}{ Oftentimes } & \multicolumn{2}{|c|}{ Always } & \multicolumn{2}{|c|}{ Missing } \\
\hline & $\mathbf{N}^{\mathbf{0}}$ & $\%$ & $\mathbf{N}^{\mathbf{0}}$ & $\%$ & $\mathbf{N}^{\mathbf{0}}$ & $\%$ & $\mathbf{N}^{\mathbf{0}}$ & $\%$ & $\mathbf{N}^{\circ}$ & $\%$ \\
\hline Cares about the values of nurses & 0 & 0,0 & 0 & 0,0 & 4 & 6,3 & 59 & 93,7 & 0 & 0.0 \\
\hline Cares about patient values & 0 & 0,0 & 0 & 0,0 & 4 & 6,3 & 59 & 93,7 & 0 & 0.0 \\
\hline Discuss ethical issues related to caring for your team & 0 & 0,0 & 9 & 14,3 & 27 & 42,9 & 27 & 42,9 & 0 & 0.0 \\
\hline Controls respect for the patient's privacy and individuality & 0 & 0,0 & 0 & 0,0 & 20 & 31,7 & 42 & 66,7 & 1 & 1,6 \\
\hline It guarantees legal conditions for care and professional practice & 0 & 0,0 & 4 & 6,3 & 13 & 20,6 & 46 & 73,0 & 0 & 0.0 \\
\hline
\end{tabular}


Regarding the activities developed in the Care Management component (table 2), we observed a variation from 21 to 56, with a mode of 54 and an average of 46.40 with a standard deviation of 7.461. This component also makes its distribution fall into the positive side of the scale.
We can see (Table 2), once again, that the manager nurses who took part in the study have an average higher than the midpoint of the subscale. In view of the results, we can say that managers develop activities in such a way that, overall, regarding Care Management, their intervention is positive.

Table 2. Care Management.

\begin{tabular}{|c|c|c|c|c|c|c|c|c|c|c|}
\hline \multirow{2}{*}{ Dimensions } & \multicolumn{2}{|c|}{ Never } & \multicolumn{2}{|c|}{ Few times } & \multicolumn{2}{|c|}{ Oftentimes } & \multicolumn{2}{|c|}{ Always } & \multicolumn{2}{|c|}{ Missing } \\
\hline & $\mathbf{N}^{\mathbf{o}}$ & $\%$ & $\mathbf{N}^{\mathbf{0}}$ & $\mathbf{N}^{\mathbf{0}}$ & $\%$ & $\%$ & $\mathbf{N}^{\mathbf{o}}$ & $\%$ & $\mathbf{N}^{\mathbf{0}}$ & $\%$ \\
\hline Discuss decisions about care with nurses & 1 & 1,6 & 3 & 4,8 & 25 & 39,7 & 34 & 54,0 & 0 & 0.0 \\
\hline Promotes clinical decision making & 2 & 3,2 & 4 & 6,3 & 25 & 39,7 & 32 & 50,8 & 0 & 0.0 \\
\hline Monitors the execution of care in a planned manner & 2 & 3,2 & 10 & 15,9 & 31 & 49,2 & 20 & 31,7 & 0 & 0.0 \\
\hline Provides for and ensures the means and resources necessary to provide care & 1 & 1,6 & 20 & 31,7 & 41 & 65,1 & 0 & 0.0 & 1 & 1,6 \\
\hline Discuss the risks of patients regarding the care and conditions of the service & 0 & 0,0 & 4 & 6,3 & 26 & 41,3 & 33 & 52,4 & 0 & 0.0 \\
\hline Ensures safe staffing according to the profession's quality standards & 5 & 7,9 & 11 & 17,5 & 26 & 41,3 & 21 & 33,3 & 0 & 0.0 \\
\hline Analyzes and assesses the quality of care and implements corrective measures & 2 & 3,2 & 6 & 9,5 & 30 & 47,6 & 25 & 39,7 & 0 & 0.0 \\
\hline Guides more complex care & 4 & 6,3 & 6 & 9,5 & 25 & 39,7 & 28 & 44,4 & 0 & 0.0 \\
\hline Develop continuous quality improvement plans & 3 & 4,8 & 8 & 12,7 & 35 & 55,6 & 17 & 27 & 0 & 0.0 \\
\hline $\begin{array}{l}\text { Prepares, applies, evaluates and updates guiding procedures for the use of } \\
\text { equipment and material }\end{array}$ & 2 & 3,2 & 12 & 19,0 & 27 & 42,9 & 22 & 34,9 & 0 & 0.0 \\
\hline $\begin{array}{l}\text { Contributes to the development of good practices, through the proper use of } \\
\text { material resources existing in the unit }\end{array}$ & 0 & 0,0 & 4 & 6,3 & 25 & 39,7 & 34 & 54,0 & 0 & 0.0 \\
\hline $\begin{array}{l}\text { It ensures safe environments by identifying, managing risks and introducing } \\
\text { corrective measures }\end{array}$ & 0 & 0 & 3 & 4,8 & 30 & 47,6 & 30 & 47,6 & 0 & 0.0 \\
\hline $\begin{array}{l}\text { Manages serious clinical situations, both for patients and families and for the } \\
\text { team }\end{array}$ & 1 & 1,6 & 5 & 7,9 & 26 & 41,3 & 30 & 47,6 & 1 & 1,6 \\
\hline
\end{tabular}

Table 3 shows the Human Resources Management component, which varies from 20 to 56, with a mode of 55 and an average of 45.38 with a standard deviation of 8,481 , this component also distributes in the positive direction of scale.

Table 3. Human Resource Management.

\begin{tabular}{|c|c|c|c|c|c|c|c|c|c|c|}
\hline \multirow{2}{*}{ Dimensions } & \multicolumn{2}{|c|}{ Never } & \multicolumn{2}{|c|}{ Few times } & \multicolumn{2}{|c|}{ Oftentimes } & \multicolumn{2}{|c|}{ Always } & \multicolumn{2}{|c|}{ Missing } \\
\hline & $\mathrm{N}^{\mathbf{0}}$ & $\%$ & $\mathrm{~N}^{\mathbf{0}}$ & $\%$ & $\mathbf{N}^{0}$ & $\%$ & $\mathrm{~N}^{\mathbf{0}}$ & $\%$ & $\mathbf{N}^{\mathbf{0}}$ & $\%$ \\
\hline Promotes meetings with nurses & 1 & 1,6 & 8 & 12,7 & 17 & 27,0 & 37 & 58,7 & 0 & 0.0 \\
\hline Watch the shift change & 12 & $\begin{array}{l}19, \\
0\end{array}$ & 9 & 14,3 & 10 & 15,9 & 30 & 47,6 & 2 & 3,2 \\
\hline Evaluates the performance of nurses & 5 & 7,9 & 5 & 7,9 & 11 & 17,5 & 42 & 66,7 & 0 & 0.0 \\
\hline Coordinates the employee integration process and assumes a role of reference & 4 & 6,3 & 4 & 6,3 & 12 & 19,0 & 43 & 68,3 & 0 & 0.0 \\
\hline Calculates the needs of nurses according to the conditions of the services & 4 & 6,3 & 10 & 15,9 & 7 & 11,1 & 42 & 66,7 & 0 & 0.0 \\
\hline $\begin{array}{l}\text { It affects nurses according to the intensity and complexity of care, through } \\
\text { methodologies that allow calculating, in advance, the number of hours of care } \\
\text { needed }\end{array}$ & 12 & $\begin{array}{l}19 \\
0\end{array}$ & 8 & 12,7 & 21 & 33,3 & 22 & 34,9 & 0 & 0.0 \\
\hline $\begin{array}{l}\text { Creates, maintains and develops cohesion, team spirit and a work } \\
\text { environment, managing conflicts }\end{array}$ & 1 & 1,6 & 5 & 7,9 & 21 & 33,3 & 36 & 57,1 & 0 & 0.0 \\
\hline Assign nurses according to patient needs & 5 & 7,9 & 11 & 17,5 & 13 & 20,6 & 33 & 52,4 & 1 & 1,6 \\
\hline Promotes team commitment and motivation (global vision) & 0 & 0,0 & 6 & 9,5 & 24 & 38,1 & 33 & 52,4 & 0 & 0.0 \\
\hline Ensures formal communication mechanisms for the team and other employees & 0 & 0,0 & 9 & 14,3 & 25 & 39,7 & 29 & 46,0 & 0 & 0.0 \\
\hline Acts as a trainer in the multi and intra disciplinary team & 4 & 6,3 & 12 & 19,0 & 29 & 46,0 & 18 & 28,6 & 0 & 0.0 \\
\hline $\begin{array}{l}\text { Promotes and assesses the professional satisfaction of nurses and other } \\
\text { employees }\end{array}$ & 5 & 7,9 & 14 & 22,2 & 28 & 44,4 & 16 & 25,4 & 0 & 0.0 \\
\hline Creates and maintains the conditions for cooperative work within the team & 0 & 0,0 & 5 & 7,9 & 21 & 33,3 & 36 & 57,1 & 1 & 1,6 \\
\hline
\end{tabular}

As it can be seen in Human Resource Management, although the score attributed by manager nurses continues to be positive, it demonstrates that there are activities that need to be reconsidered, among which are: attending shift changes; affecting nurses according to the intensity and complexity of care; acting as a training nurse and promote the assessment of the professional satisfaction of nurses and other professionals.

The Political Intervention and Advisory component (Table 4) ranges from 10 to 24 , with a mode of 18 and an average of 17.97 with a standard deviation of 3.545 ; this component also makes its distribution in the positive sense of the scale, with only one missing answer. 
Table 4. Political Intervention and Advisory.

\begin{tabular}{|c|c|c|c|c|c|c|c|c|c|c|}
\hline \multirow{2}{*}{ Dimensions } & \multicolumn{2}{|c|}{ Never } & \multicolumn{2}{|c|}{ Few times } & \multicolumn{2}{|c|}{ Oftentimes } & \multicolumn{2}{|c|}{ Always } & \multicolumn{2}{|c|}{ Missing } \\
\hline & $\mathbf{N}^{\mathbf{0}}$ & $\%$ & $\mathbf{N}^{\mathbf{0}}$ & $\%$ & $\mathbf{N}^{\mathbf{0}}$ & $\%$ & $\mathbf{N}^{\mathbf{0}}$ & $\%$ & $\mathbf{N}^{\mathbf{0}}$ & $\%$ \\
\hline Participates in the definition and implementation of hospital health policies & 5 & 7,9 & 13 & 20,6 & 32 & 50,8 & 12 & 19,0 & 1 & 1,6 \\
\hline Participates in the strategic planning of the service & 4 & 6,3 & 5 & 7,9 & 28 & 44,4 & 25 & 39,7 & 1 & 1,6 \\
\hline Prepare service reports & 7 & 11,1 & 10 & 15,9 & 28 & 44,4 & 17 & 27,0 & 1 & 1,6 \\
\hline $\begin{array}{l}\text { Conceives and operationalizes projects in the service, involves and involves } \\
\text { the team in the development and implementation of organizational projects }\end{array}$ & 5 & 7,9 & 8 & 12,7 & 27 & 42,9 & 22 & 34,9 & 1 & 1,6 \\
\hline $\begin{array}{l}\text { Adapts material resources to needs, taking into account the cost-benefit } \\
\text { ratio }\end{array}$ & 0 & 0,0 & 9 & 14,3 & 18 & 28,6 & 35 & 55,6 & 1 & 1,6 \\
\hline $\begin{array}{l}\text { Participates in working groups and committees in the area of clinical and } \\
\text { non-clinical risk management }\end{array}$ & 13 & 20,6 & 15 & 23,8 & 19 & 30,2 & 15 & 23,8 & 1 & 1,6 \\
\hline
\end{tabular}

Regarding the area of Political Intervention and Advisory, it is worth highlighting the need for nurse managers to ensure more participation in the definition and implementation of health policies as well as greater participation in working groups and commissions in the area of clinical and non-clinical risk management.

Table 5. Professional Development.

\begin{tabular}{|c|c|c|c|c|c|c|c|c|c|c|}
\hline \multirow{2}{*}{ Dimensions } & \multicolumn{2}{|c|}{ Never } & \multicolumn{2}{|c|}{ Few times } & \multicolumn{2}{|c|}{ Oftentimes } & \multicolumn{2}{|c|}{ Always } & \multicolumn{2}{|c|}{ Missing } \\
\hline & $\mathbf{N}^{\mathbf{0}}$ & $\%$ & $\mathbf{N}^{\mathbf{0}}$ & $\%$ & $\mathbf{N}^{\mathbf{0}}$ & $\%$ & $\mathbf{N}^{\mathbf{0}}$ & $\%$ & $\mathbf{N}^{\mathbf{0}}$ & $\%$ \\
\hline Promotes evidence-based nursing & 4 & 6,3 & 4 & 6,3 & 25 & 39,7 & 30 & 47,6 & 0 & 0.0 \\
\hline Promotes formal and informal team training & 2 & 3,2 & 7 & 11,1 & 19 & 30,2 & 35 & 55,6 & 0 & 0.0 \\
\hline Encourages nurses to self-train & 1 & 1,6 & 5 & 7,9 & 16 & 25,4 & 41 & 65,1 & 0 & 0.0 \\
\hline $\begin{array}{l}\text { It provides spaces for reflection on practices in order to promote the team's } \\
\text { commitment to managing their own skills }\end{array}$ & 4 & 6,3 & 12 & 19,0 & 28 & 44,4 & 19 & 30,2 & 0 & 0.0 \\
\hline
\end{tabular}

When analyzing the Professional Development component, represented in table 5, we see a variation from 6 to 16, with a mode that occurs between the 15 and 16, the average of 13.19 with a standard deviation of 2.711 . This component also makes its distribution in the positive sense of the scale. We can affirm that the dimension that needs more attention is to provide spaces for reflection on practices in order to promote the team's commitment to the management of their own skills.

The activities of manager nurses who took part of this sample represent all areas of expertise of the manager nurse, and it should be noted that most of them do their activities in all domains of "Always", noting some weaknesses in the Political Intervention and Advisory dimension, considering that only "Sometimes" they do it. For the "Never" option, no management activity has a frequency greater than ten.

\section{Discussion}

The sample is mostly female (61.9\%). Historical perspective of nursing and checking the 2018 Report and Accounts of the OE, this validates "As of December 31, 2018, there were 73912 members of the ON. Of the total number of members, 60,737 are female and 13175 are male".

Regarding the age groups of manager nurses and leaders, in this sample the most representative age group is 51 and 60 years old, with $39.7 \%$. The distribution of manager nurses by years of professional practice ranged between 9 and 40 years of professional practice, with two more representative records aged between 20 and 29 years and 30 and 40 years of age, both $(33.3 \%)$ of representativeness. With regard to the time of professional practice in the management area, it was found that nurses have between 0 to 31 years of experience in the management area, verifying that the highest percentage of nurses who perform this management function ranges from 0 to 9 years $(63.5 \%)$.

The academic qualifications held by manager nurses $(15.9 \%)$ are postgraduate courses in specific areas other than management. Nevertheless, about $(36.5 \%)$ of the nurses participating in the study have a postgraduate degree in management and a master's degree (17.5\%).

The analysis of the Professional Ethical and Legal Practice component made it possible to conclude with the opinion of the participants who are "always" concerned with the values of nurses and the values of patients, both with $(93.7 \%)$, the lowest value being found in the dimension "discusses ethical issues related to the care of your team" - (42.9\%). These results are in line with other studies that value the imperativeness for a Manager Nurse to focus on the client and the nurse, promoting an ethical and legal professional environment. Lelli, L., Bernardino, E., Peres, A., Fabriz, 1., [13] express the importance of leadership skills in professional practice, in the organization, trust and guidance of the work team.

In the Care Management component, it is noticed that this dimension discusses decisions about care with nurses $(54.0 \%)$ answer that they "always" put this skill into practice. In this premise, one of the ways to ensure that this skill is developed and improved in the environment of the Nurse Manager practice is that it should be increased by formal training. In this context, the study by Fradique, M. \& Mendes, L. [14] lists a suggestive structural model, in which nursing leadership is directly related to the quality of nursing care provided, with the "client" being the focus of the process.

Estimating the Human Resources Management component similarly to the care management category, most Manager 
Nurses answer "always" to almost all questions, except for the dimensions: he acts as a trainer in the multi and infra disciplinary team, only $(28,6 \%)$ refer "always"; promotes and evaluates the professional satisfaction of nurses and other collaborators, (25.4\%) respond "always $\ "$ ". Similarly, the authors listed the need for Manager Nurses to undertake training in the area of management as an important premise, aiming to change their leadership style, promoting the self-reflection of the Manager Nurses and consequently endeavoring practices more appropriate to their work contexts $[4,6,7,13]$.

In the Political Intervention and Advisory component area, they responded that they "always" adapt material resources to needs, taking into account the cost-benefit ratio (55.6\%). Finally, in the Professional Development component, four dimensions were addressed, and it was found that about more than half of the answers were "always", when they are positioned in the face of nurses' stimulation to self-training (65.1\%).

Comparatively, several studies have cataloged the importance of the nurse managers' leadership capacity as a key competence in management functions. However, they still favor factors such as: negotiation, analysis and problem solving; commitment and results orientation; communication and knowledge sharing; teamwork and decision making $[4,6$, $7,14,15]$.

In this discussion, we consider important the fact that other authors refer as management skills of nurses the leadership style as a decisive factor for the motivation of the team. We corroborate the various studies, when they mention that the improvement of the employees' professional satisfaction is crucial for the high quality of care and are the guarantee of efficiency in the provision of health care, $[4,6,7,15]$. The Manager Nurse is considered to be the professional who has the skills to match the real "engine" offering energy and motivation for change in healthcare organizations.

\section{Conclusion}

We found out that the need for training is evident in the different dimensions of skills: Ethical and Legal Professional Practice, Care Management, Human Resource Management, Political Intervention and Professional Advice and Development.

We prove that the majority of manager nurses do not have specific training in the management area that underpins the management position they occupy with knowledge. The completion of this investigation revealed an indisputable need to implement training practices in the contexts of the nursing leaders, in order to improve the advanced skills of the nurse managers and leaders.

The use of a questionnaire is considered to be a weakness of the study, since it didn't allow clarification of doubts the nurses might have had when answering it. The lack of verbal contact prevented further clarification.

This study contributed to the awareness that the Manager Nurse in this island region has training needs in the context of work in terms of advanced added skills. it is our intention that the most relevant points of this study serve as subsidies for the realization of new studies in this same scope.

\section{Acknowledgements}

In the course of this work, several people actively contributed to its accomplishment. Some people had an interventional role, while others a more influential one. A special acknowledgement to $\operatorname{Dr}^{\mathrm{a}}$ Maria Manuela Martins; thank you.

Special thanks to the nurses who agreed to participate in this study, for their collaboration and willingness to share experiences.

\section{References}

[1] Rocha, MCJ; Sousa, P. \& Martins, M. (2016) The opinion of nurse directors on the intervention of the head nurse. Nursing Research. 18, Vol. 2, 89-105.

[2] Ceitil, M. (2016). Skills Management and Development. 2 ed, Lisboa: Edições Silabo, Lda.

[3] Costa, T. (2018). Contemporary Management: Principles, Trends and Challenges. $2^{\mathrm{a}}$ ed. Lisboa. Edições Silabo.

[4] Chipeta, E., Bradley, S., Manda, W., McAuliffe, E. (2016). Working relationships between obstetric care staff and their managers: a critical incident analysis. BMC Health Services Research, Malawi. 1-9.

[5] Moura, A., Bernardes, A. \& Balsanelli, A. (2017) Leadership and job satisfaction in nursing: an integrative review. Acta Paulina Enfermagem, 30 (4), 442-450.

[6] Camelo, S., Silva, V., Soares, M., Resck, Z., Chaves, 1., Santos, F. (2016). Leadership practices in hospital nursing: a self of managing nurses. Rev Esc Enferm USP. Brasil, 1-8.

[7] Munyewende, P., Levin, J. \& Rispel, L. (2016). An evaluation of the competencies of primary health careclinic nursing managers in two South African provinces. Global Health Action. Africa do Sul, 9 dez. 2016, 1-11.

[8] Ordem dos Enfermeiros. (2015). REPE e Estatuto. Lisboa: Ordem dos enfermeiros.

[9] Dec. Law no 161/96. D. R. I Série - A. No 205 (1996-09-04), 2959-2962. (Regulamento do Exercício Profissional do Enfermeiro).

[10] Regulation No. 101/2015 - Advanced Competence in Management is regulated. Diário da República. 10 de março de 2015, Vol. 2o Série no 48, 5948-5952.

[11] Regulation No. 76/2018. D. R. II Série. No 21 (2018-01-30), 3478-3487.

[12] Dec. Law no 71/2019. D. R. I Série, N ${ }^{a} 101$ (2019/05/27), 2626-2642.

[13] Lelli, L., Bernardino, E., Peres, A., Fabriz, 1., (2012). Management strategies for the development of nursing skills in a teaching hospital. Cogitare Enfermagem. 2, Abril - Junho de 2012, Vol. 17, $262-269$. 
[14] Fradique, M. \& Mendes, L. (2013). Effects of leadership on improving the quality of nursing care. Revista de Enfermagem de Referência, III (10), 45-53.
[15] Vesterinen, S., Suhonen, M., Isola, A., Paasivaara, L. (2012). Nurse Managers' Leadership Styles in Finland. Nursing Research and Practice. Finlândia, Volume 2012, Article ID 605379, 1-8. 